\title{
Google proposes evidence-based search rankings
}

$\mathrm{O}$ $\mathrm{n}$ the second page of search results for "autism" on Google .ca, tucked between WebMD and the Centers for Disease Control and Prevention, is an article with a rather ominous headline: "U.S. Media Blackout: Italian Courts Rule Vaccines Cause Autism." If you are a conspiracyloving, antivaccine crusader, you probably clicked on that link with enough gusto to sprain a finger. The article has been shared more than 25000 times, which could explain the relatively lofty ranking. But it may soon plummet to the Web's nether regions if Google follows through on its proposal to incorporate trustworthiness into its search engine.

In a recent paper, Google introduced the idea of knowledge-based trust, a "trustworthiness score" assigned to a website based on the accuracy of the information it contains. Currently, a website's search ranking is boosted by the number of inbound links, even if the site is bloated with misinformation. To improve the quality of the sources suggested by its search engine, Google has proposed using a "sophisticated probabilistic model" to estimate the correctness of information extracted from websites. "A source that has few false facts is considered to be trustworthy," states the paper.

"There is so much misinformation floating around the Internet," Timothy Caulfield, Canada Research Chair in Health Law and Policy, wrote in an email. "These bits of information can be used to fuel misunderstandings about health, be it in the context of diet, exercise or vaccination. With so much information - of vastly different quality available at our fingertips, it is easy for things like confirmation bias to take over. So, the idea of highlighting the trustworthiness of a website seems like a terrific idea."

Of course, it's one thing to propose a means to ferret out the truth but quite another to implement it. Though the evidence base is strong in some areas of

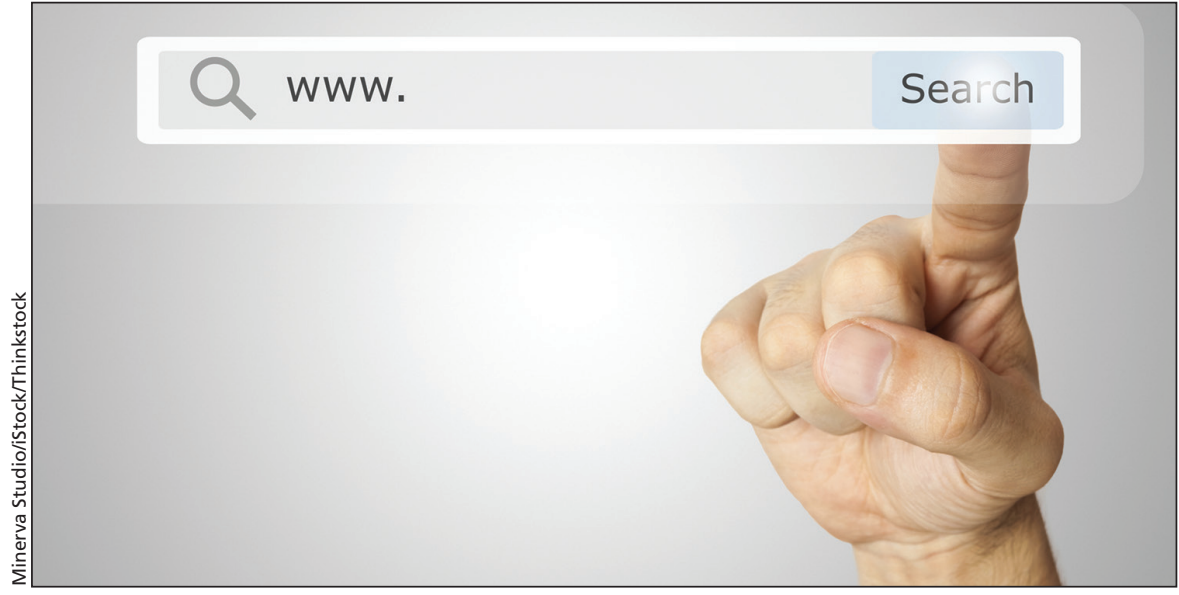

Internet search rankings are based more on popularity than accuracy.

health, such as the efficacy and safety of vaccines, it is much weaker in others. Medicine is also complicated, often grey and open to interpretation, so iron-clad "truths" may be scarce for some topics. How feasible is it, for example, to create a science-based ranking of the multitude of websites offering information about nutrition and weight management?

"While I will readily agree that nutrition science is nowhere near as specific and drilled down as the world thinks it is, I would hope a serious undertaking would at the very least lower the search rankings of the most predatory and inane pages," Dr. Yoni Freedhoff, medical director of the Bariatric Medical Institute in Ottawa, wrote in an email. "As to whether or not that will be successful, it's difficult to say."

There is also no guarantee that more trustworthy sources of information will offer the greatest value to the most people. An impenetrable text that nobody reads provides little benefit, no matter how accurate. There is often a trade-off between the quality of a source of medical information and its utility, according to Dr. Mike Evans, founder of the Evans Health Lab, which produces the popular Whiteboard Med School series.

"The simple answer would be to focus on quality, but I think we have to take it another step and think about the way we bring it to the public so it is understandable and usable," Evans wrote in an email.

But even if Google searches return information that is both more accurate and more understandable, Web users should still show caution when making decisions about their health based on Web searches. "I strongly believe that practising 'medicine through Internet' is super dangerous," Dr. Wojtek Michalowski, a professor of health informatics at the Telfer School of Management in Ottawa, wrote in an email. "A lot of people go to the Internet to second-guess their physician, to learn if they have any disease, etc. And people believe that if information was retrieved from a site that 'looks good' then the information must be reliable."

The harshest criticisms of Google's proposed changes can be found on websites for alternative media, natural health and those that promote ideas contrary to scientific consensus. It will open the door for "Google to homogenize thought and become global arbiters of truth, with the ability to send content it declares as 'untrue' into the dustbin of obscurity," warned an article on the Natural Society website. For other examples, simply Google "knowledge-based trust" and "Orwellian." - Roger Collier, CMAJ 